\title{
Globalization in regions and program design to multicultural competence development
}

\author{
Tatiana Anatolyevna Zhukova ${ }^{1,2 *}$, Timur Segeevich Selimov², Vladimir Igorevich \\ Bogoslovskiy $^{3}$, Olga Aleksandrovna Yankevich $^{4}$, and Natalia Valeryevna Startseva ${ }^{5}$ \\ ${ }^{1}$ Financial University under the Government of the Russian Federation, Department of Foreign \\ Languages and Intercultural Communication, Moscow, Russia \\ ${ }^{2}$ Moscow Pedagogical State University, Department of the English language and digital technologies \\ in education, Moscow, Russia \\ ${ }^{3}$ Herzen State Pedagogical University, Department of digital technologies in education, St. Petersburg, \\ Russia \\ ${ }^{4}$ Samara State University of Social Sciences and Education, Department of physics, mathematics and \\ methods of teaching, Samara, Russia \\ ${ }^{5}$ Samara State University of Social Sciences and Education, Foreign Languages Department, Samara, \\ Russia
}

\begin{abstract}
In this paper, the matter of how the process of globalization in regions influences the process of development of program design aimed at forming and improving multicultural competence is brought up. One way to comply with the demands is to define and develop new strategies that can make a teacher's evaluation a successful process of improvement of multicultural competence. Better learning and teaching outcomes are to be reached - since the programs designed within the above-mentioned framework would correlate with the need of students and demands of modern education in a region, which basis lies in the matter of globalization. A literature analysis of available research was conducted. As a plan program design is not a linear process, it may be necessary to alter the content or sequencing to offer a possible mechanism to optimize the process of cooperation between the regions, to identify new factors and search for new practices to improve readiness to change (as a significant component of multicultural competence) and to offer case-study as one of the possible methods to better the process of multicultural competence development. We consider the proposed strategies as the main results of the research.
\end{abstract}

Keywords: regional policy, perspectives to program design development, globalization

\section{Introduction}

The article provides opportunities for practicing and applying the strategies of planning the design of regional programs, which are aimed at forming multicultural competence. For this

*Corresponding author: tatianazhu@mail.ru 
paper, the authors consider important issues in program design taking into account the existing practices in each region, on the one hand, and the constantly changing multicultural processes in the region, on the other hand, which undoubtedly has an impact on the process of formation and improvement of multicultural competence.

Unfortunately, "as regional education systems vary in terms of structure and curricular content, it can be difficult to make spatial or temporal comparisons when assessing their performance" [1].

The authors agree with the position of the researchers that in order to interpret the inputs, outcomes of programs, regional policy is compiled according to the regional obstacles and needs as well as the specifics of multicultural processes [2-4].

Although design is "how-to-do-it" regional programs, the description of the strategies needs to be done at a general level so that they can be applied in a large variety of particular circumstances. Such a description will only come to life if there are many examples of actual applications for the following positions.

\section{Methods}

The authors use a theoretical and empirical review of the literature and a conceptual framework. The theories reviewed in this paper serve the purpose of explaining the problem of study. The empirical studies lend support to the theories, propose alternate suppositions, and highlight the need for further research. The conceptual framework identifies obstacles to the instruction of the program design.

\section{$3 \quad$ Results}

Today's "societies thus place challenging demands on teachers and researchers, who are confronted with the complexity in their practice" [5]. The authors provide the current views on the problem.

1. First of all, it is important to outline the significant functions of regional educational policy. Thus, many researchers [5-7], have contributed to the development of the following idea, studying description the way "regional system refers to four key functions: the informative function which becomes evident in the direct exchange, and in providing the bridge between, practice and knowledge among researchers and institutions; professional development which offers opportunities for further researchers development; the psychological function that encourages and strengthens individual members and the political function based on the power of well-structured" [8] research work to influence regional policies.

2. Existing research to date has developed an idea of understanding what a regional-based program is. For example, in a regional-based program, it is important to set up the goal, the conceptual framework, and the plan, guide the development of regional program content $[9,10]$. Undoubtedly, awareness of the regional aspect concerned in the process of improvement of multicultural competence is necessary. In this regard, it is important to emphasize the following, regular interaction among higher and secondary institutions within the regional programs is not only encouraged, but also expected. Programs themselves may occur initially in one region as a foundation for their application in another region [11].

3. There are also a lot of researchers on how to encourage regional programs $[12,13]$ development in particular, which can be used to guide the presentation of items to be 
discussed. The principles derived from this research include the one about "the necessity of repetition and thoughtful material processing", the importance of taking into account individual and regional differences, and on researcher attitudes and motivation [14]. Program design must make the connection between the research and the design practice.

Summarizing the above, it is important to note the following: today there is a clear idea of the necessity and the sense of regional programs, on the one hand, and the possibility of their improvement, on the other - due to constantly changing demands, interests and new needs. In this connection, the authors attempted to give their strategies to improve the process of designing regional programs, the purpose of which is to form and improve multicultural competence in the context of globalization.

\section{Discussion}

The theoretical contributions have greatly expanded the role of educational institutions in the development of regional programs. It is equally important to understand what both teachers and learners have to say about "the impulse this movement has had on the effective realization" [14] of regional programs with culturally diverse impact in a higher education institution. It is important to do so, because teachers are responsible for implementing programs based on regional researches and considered as the perspectives.

\subsection{Strategy 1}

Research policy fosters cooperation between educational institutions, research institutions especially on a regional level. What makes these researches in regions special?

1. The research mission is to boost the innovative capacity to do so by supporting their cooperation with educational institutions through research funding programs in the regions, which allows educational institutions to keep their ideas competitive by drawing on current scientific knowledge. Moreover, it is efficient to describe its significance in terms of research and to transfer the platform for further investigations.

2. To provide an example of innovative and international research at world education institutions is the International Research Training Group [15, 16] (IRTG) "Diversity: Mediating Difference in Transcultural Spaces" projects; because it is essential "to decide why a course is being taught and what the teachers need to do. Teachers cannot be expected to learn every aspect of the regional policy before they are allowed to use it for research purposes" [17]; to encourage communicating in everyday situations; to sustain interest and motivation; to help understand and formulate the perspectives; give insights into regions etc.). "Clusters of Excellence promote cutting-edge research which serves to strengthen the research profiles of educational institutions or educational institutions' competitive research fields" [17].

\subsection{Strategy 2}

The next important step, according to the authors of this article, should be an analysis of the factors that influence the process of designing programs aimed at developing and improving multicultural competence. In our understanding it is important to talk about external and internal factors, here are the possible and seemingly significant ones (Table 1).

Table 1. External and internal factors. 


\begin{tabular}{|l|l|}
\hline \multicolumn{1}{|c|}{ External } & \multicolumn{1}{c|}{ Internal } \\
\hline People with different background relation & Unwillingness to cooperation \\
\hline Regional experience in integration & $\begin{array}{l}\text { Different levels of readiness to cooperate with } \\
\text { other regions }\end{array}$ \\
\hline $\begin{array}{l}\text { Understanding the perspectives in integration } \\
\text { within regional policy }\end{array}$ & $\begin{array}{l}\text { The psychological ability to cooperate with other } \\
\text { regions }\end{array}$ \\
\hline $\begin{array}{l}\text { Disciplines are not oriented to integration } \\
\text { skills development }\end{array}$ & The lack of knowledge of integration \\
\hline $\begin{array}{l}\text { Psychological incapability of people with } \\
\text { different cultural backgrounds }\end{array}$ & $\begin{array}{l}\text { The lack of training to psychological readiness to } \\
\text { integration }\end{array}$ \\
\hline Different approaches in regions & $\begin{array}{l}\text { The lack of knowledge about different approaches } \\
\text { in regions }\end{array}$ \\
\hline
\end{tabular}

Summarizing the above, the authors emphasize: the program design process can be also considered in two sub-processes, environment analysis needs and the importance of organizing the regional program design process at two levels.

Personal readiness level in the design of regional programs.

The authors consider personal readiness as one of the key components of multicultural competence. We propose a series of information gap tasks to analyze students' and teachers' readiness to work with people of different multicultural backgrounds in the regions.

\subsection{Information gap task 1}

Answer key. The regional concept is the key aim of modern education. Experience in different regions is important.

Task. You have some students in your class from different regions. You understand you do not know how to organize your work with students with different multicultural backgrounds and preferences in a certain region.

\section{Preparation.}

1. Review the regional literature on the problem of the concept.

2. Analyze educational websites or discuss the problem with students from different regions about this concept.

3. Divide the class into groups of three or four. Their tasks are to imagine that they are to organize regional concepts for children at school.

4. Discuss the tasks for children with your teacher.

\subsection{Information gap task 2}

Answer Key. Although there is a growing interest in the importance of higher education systems development in a region, there is still a lack of theoretically well-grounded comparative studies in different countries. The teacher is not ready to design a regional program.

Task. You lived and worked in the eastern part of the country. Then you moved to live and work in the western part of the country. You understand you do not know how to organize your work with children with different multicultural backgrounds and preferences in a region.

1. Review the literature on the problem of regional policy in education and regional program design.

2. Analyze the teaching practice at regional schools in different countries. 
3. Work in groups and share your views on how to develop a regional educational environment and provide regional program design.

4. Make an on-line project and make a presentation.

Design Level to the design of regional programs.

Within the framework of this level, it is expedient, from the researchers' point of view, to expand the idea of "design" and consider it within the framework of case study. Case studies describe the further prospects that will put in touch with others' experience while designing regional programs, aimed at the formation of multicultural competence.

The content of the regional programs aimed at the improvement of multicultural competence consists of the ideas, items and strategies that meet the goals of the program (Fig. 1).

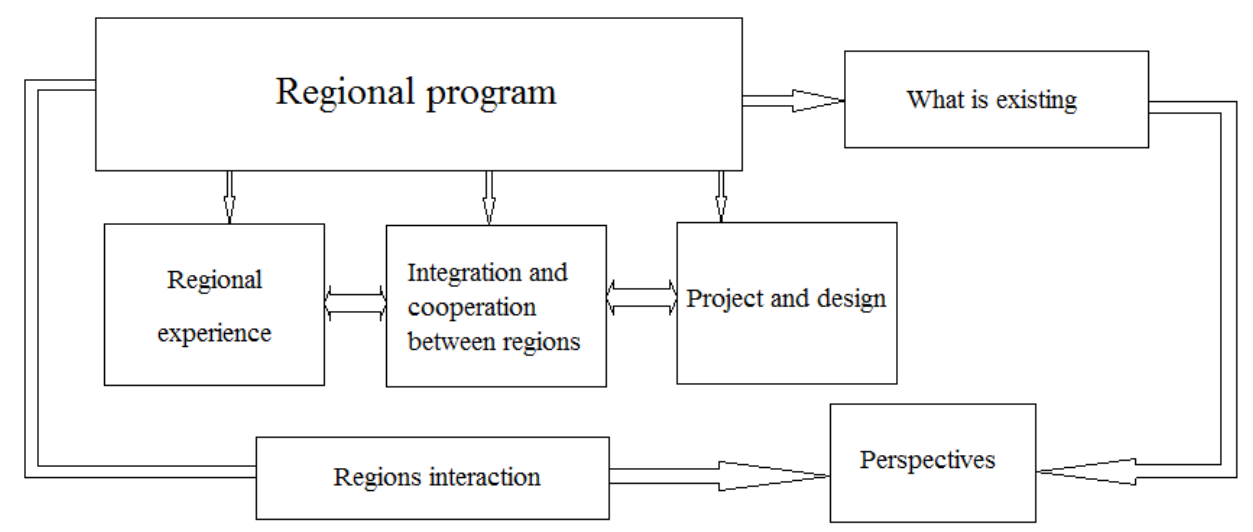

Fig. 1. Case study of regional program design.

\section{Conclusion}

This article presents the outcomes concerning the strategies of regional program design aimed at improvement of multicultural awareness that is faced with a common challenge to educate cultural diversity. Although there is a growing interest in the importance of these programs, there is still a lack of theoretically well-grounded specific researches. Topics such as factors, which influence the process of regional program design as well as levels, are not broadly discussed. This paper addresses this problem by discussing theoretical questions behind the development of the new mechanisms for the improvement of regional programs. The authors of the article focus on analyzing the positions of the Russian and foreign scientists as regards program design, one of the conditions necessary for the improvement of the foundations of levels to be held to improve the process of program design. Research in this paper shows that the decision on how to apply the design of regional programs should be left to each educational institution of the region or the country. However, in order to facilitate the integration, different regions around the world should work towards a selection of cooperation educational models, approaches and case study methods.

\section{References}


1. A. Hosseini Fatemi, G.H. Khajavy, C.W. Choi, J Intercult Comm Res, 45(4), 304-318 (2016). https://doi.org/10.1080/17475759.2016.1190776

2. H.A. Alismail, J Edu Prac, 7(11), 139-146 (2016). https://doi.org/10.19030/tlc.v2i5.1825

3. E. Bosse, Vielfalt erkunden - ein Konzept für interkulturelles Training an Hochschulen [Exploring diversity - a concept for intercultural training at universities], in G.G. Hiller, S. Vogler-Lipp (eds), Schlüsselqualifikation Interkulturelle Kompetenz an Hochschulen, 109-133 (VS Verlag für Sozialwissenschaften, 2010). https://doi.org/10.1007/978-3-531-92019-1_6

4. F. Y1lmaz, Cogent Edu, 3(1) (2016). https://doi.org/10.1080/2331186X.2016.1172394

5. J. Enders, Higher Edu, 47, 361-382 (2004). https://doi.org/10.1023/B:HIGH.0000016461.98676.30

6. M.L. Dameron, A. Camp, B. Friedmann, S. Parikh-Foxx, J Multicult Counsel Devel, 48(3), 176-190 (2020). https://doi.org/10.1002/jmcd.12176

7. J. D’Haem, P. Griswold, Edu Urban Soc, 49(1), 81-109 (2017). https://doi.org/10.1177/0013124516630602

8. C.M. Vargas, Int J Edu Devel, 20(5), 377-396 (2000). https://doi.org/10.1016/S0738-0593(99)00081-4

9. T. Ringeisen, et al., Documents on further education and internationalisation at universities, 4, 4-38 (2006)

10. V. Potishuk, J. Kratzer, J Entrep Edu, 20(1), 125-134 (2017)

11. M.N. Kokarevich, N.Z. Sizova, Proc-Soc Behav Sci, 166, 621-625 (2015). https://doi.org/10.1016/j.sbspro.2014.12.584

12. S. Nieto, et al., Identity, Community and Diversity: Retheorising multicultural curriculum for the postmodern era, in The Sage handbook of curriculum and instruction, 176-197 (2008). http://dx.doi.org/10.4135/9781412976572.n9

13. T. Zhukova, et al., Espacios, 39(10), 35 (2018). https://doi.org/s2.0-85060445299

14. V.V. Laptev, S.A. Pisareva, A.P. Tryapitsyna, Edu Soc, 57(10), 838-857 (2015). https://doi.org/10.1080/10609393.2015.1148955

15. G. H. Beckett, M. Kobayashi, Amer J Qualit Res, 4(1), 85-106 (2020). https://doi.org/10.29333/ajqr/8267

16. A. Portera, Intercult Edu, 19, 481-491 (2008)

17. M. Vaira, Higher Edu, 48, 483-510 (2004) 